\title{
INSPEÇÃO, REPARO E ANALISE DE FALHA EM UMA CALDEIRA DE RECUPERAÇÃO DE CALOR DE GÁS DE COQUERIA*
}

José Gonçalves Pacheco Júnior ${ }^{1}$ Igor Striotto Kramer Magalhães ${ }^{2}$ Kallin de Souza ${ }^{3}$

Fernando Gonçalves Materna ${ }^{4}$ Davi Fernando Soares Ferreira ${ }^{5}$

\section{Resumo}

A caldeira de recuperação de calor de gás de coqueria, denominada caldeira 22 , foi submetida à inspeção e reparo conforme os dispostos na NR13 em função de falhas repetitivas que levaram a uma perda repentina de nível de água no tubulão de vapor da Caldeira. $O$ equipamento foi inspecionado levando em consideração técnicas qualitativas e quantitativas de inspeção de equipamento, o que gerou a possibilidade de especificar o reparo. Através do reparo foi possível liberar a caldeira para produção de vapor. Com os dados da inspeção foi realizada uma análise de falha por um grupo multidisciplinar com objetivo de determinar a causa raiz dos modos de falhas detectados durante a inspeção do equipamento: espessura de isolamento térmico inadequado e operação inadequada após detecção de vazamento de água no equipamento. Ações de controle foram definidas e replicadas para as outras caldeiras dessa coqueria. Assim sendo a caldeira 22 está operando em segurança conforme especificação do projeto e com os reparos preventivos já determinados.

Palavras-chave: caldeira de recuperação de calor; inspeção e reparo de caldeira; NR13; analise de falha.

\section{INSPECTION, REPAIR AND FAILURE ANALYSI IN A HEAT RECOVERY BOILER THAT USE COKE PLANT GAS}

\section{Abstract}

The heat recovery boiler in the Coke Plant, called 22, was subjected to inspection and repair set forth in NR13 because of repeated failures which led to sudden loos of water level in the boiler drum. The boiler was inspected taking into account qualitative and quantitative equipment inspection techniques, which generated the possibility of specifying the repair. Through the repair it was possible to release the boiler for steam production. With the inspection information, a failure analysis was performed by a multidisciplinary group to determine the root cause of failure modes detected during equipment inspection: inadequate thermal insulation thickness and inadequate operation after detection of water leakage in the equipment. Control actions were defined and replicated to the other boilers in this coke plant. Then boiler 22 is operating safely according to the project specification and with the preventive repairs already determined.

Keywords: Heat recovery boiler; Boiler inspection and repair; NR13; Failure analysis.

1 Engenheiro mecânico, especialista, profissional habilitado NR13, engenharia de manutenção \& expertise/manutenção central, thyssenkrupp CSA Siderúrgica do Atlântico , Rio de Janeiro, Rio de Janeiro e Brasil. 
2 Engenheiro mecânico, especialista, engenheiro de manutenção IV, engenharia de manutenção/Coqueria, thyssenkrupp CSA Siderúrgica do Atlântico, Rio de Janeiro, Rio de Janeiro e Brasil.

3 Engenheira mecânica, engenheira de manutenção Mecânica I, engenharia de manutenção \& expertise/manutenção central, thyssenkrupp CSA Siderúrgica do Atlântico, Rio de Janeiro, Rio de Janeiro e Brasil.

4 Técnico especialista de produção IV, produção de vapor/coqueria, thyssenkrupp CSA Siderúrgica do Atlântico , Rio de Janeiro, Rio de Janeiro e Brasil.

5 Engenheiro de produção, especialista, engenheiro de manutenção III, engenharia de manutenção \& expertise/manutenção central, thyssenkrupp CSA Siderúrgica do Atlântico , Rio de Janeiro, Rio de Janeiro e Brasil. 


\section{INTRODUÇÃO}

Em uma siderúrgica integrada, o coque é um dos principais combustíveis, esse material é fabricado através da queima controlada do carvão mineral nas coquerias. A queima do carvão gera gases em torno de $1000^{\circ} \mathrm{C}$ que são aproveitados em caldeiras, que segundo Macintyre [1], são equipamentos destinados a mudar o estado da água, do líquido para o vapor, afim de ser usado em acionamento de máquinas motrizes, que neste caso em especifico uma turbina a vapor para a geração de energia elétrica.

No ano de 2016, uma série de paradas de emergência por furo na caldeira 22 dessa coqueria, afetou a produção de energia elétrica e por força da NR13, que é a norma regulamentadora brasileira que trata sobre o tema de caldeiras, tivemos que realizar uma inspeção de segurança excepcional no equipamento e reparo. Pelliccione [2] argumenta que cabe a atividade de inspeção zelar pela integridade das instalações e equipamentos garantindo a confiabilidade operacional, diagnosticando e mitigando os diversos processos de deterioração, fazendo uso então das diversas técnicas de inspeção. Nesse caso da caldeira 22 foram utilizadas técnicas com caráter qualitativo e outras com caráter quantitativo para a determinação do modo de falha para que o reparo pudesse ser definido.

Kardec [3] conceitua que os modos de falha são as categorias de falha como: fratura dúctil ou frágil, corrosão, erosão fluência, vibração, folga e outros, já a causa é o meio pelo qual um elemento particular do projeto ou do processo resulta em um modo de falha. Durante a inspeção o modo de falha verificado foi corrosão, que Gentil [4] define como a deterioração de um material, geralmente metálico, por ação a química ou eletroquímica do meio ambiente associada ou não a esforços mecânicos.

Nesta siderúrgica a figura do profissional habilitado em NR13 está locado na engenharia de manutenção centralizada, o que significa em um suporte técnico especializado para as áreas de manutenção e operação que tenham caldeiras, vasos de pressão e tubulação, colaborando com Kardec [3] que destaca o papel da engenharia de manutenção como: aumentar a segurança, eliminar problemas crônicos, dar suporte a execução, fazer análise de falha entre outros.

A inspeção realizada serviu de base para que pudéssemos definir de forma assertiva o reparo e que fizéssemos uma análise de falha, metodologia que, basicamente, identifica a causa raiz do problema e sugere a ação de bloqueio para os modos de falha. As análises de falhas devem ser realizadas por um grupo multidisciplinar, formados por engenheiros e técnicos de manutenção e operação, porque segundo Kardec [3] está provado que esse tipo de grupo apresenta maior produtividade pela complementariedade de conhecimentos, além da vantagem de decisões colaborativas para a condição de quebra zero e fornece maior disponibilidade e confiabilidade para os ativos.

Em síntese o trabalho que será apresentado tem como objetivo descrever em linhas gerais o equipamento, a inspeção realizada, a análise de falha feita, a identificação dos modos de falha, apresentar a causa raiz e as medidas de controle que foram colocadas em prática.

\section{MATERIAIS E MÉTODOS}

O coque é uma das matérias primas mais importante no processo produtivo do aço em uma siderúrgica integrada, este é produzido a partir da queima controlada do 
carvão em fornos especialmente projetados para essa finalidade, nas coquerias. Com a necessidade das siderúrgicas se tornarem cada vez mais ecológicas e sustentáveis, desenvolveu-se uma tecnologia de produção de coque que permite a queima total de todo o volátil presente no carvão mineral, em função disso há uma grande geração de energia na forma de calor que alcança temperatura superior a $1000^{\circ} \mathrm{C}$, de forma a aproveitar o calor gerado são introduzidas nessas coquerias caldeiras de recuperação de calor.

Caldeiras são equipamentos projetados para produzir e armazenar vapor em seu interior com pressão superior à pressão atmosférica. As caldeiras utilizadas na coqueria são do tipo aquatubular que segundo Macintyre [1], o aquecimento se faz externamente a um feixe de tubo contendo água e em comunicação a um ou mais reservatórios ou tambores. Em função da alta complexidade e do risco associado a esse tipo de equipamento, no Brasil existe a norma regulamentadora $n^{\circ} 13$ que trata de caldeiras, vasos de pressão e tubulações.

A coqueria alvo do estudo desse trabalho é equipada com 12 equipamentos de geração e acúmulo de vapor, que tem configuração vertical, com 1 tambor, 4 paredes de água, 2 super aquecedores, 2 evaporadores e 1 economizador, produzindo vapor super aquecido a uma vazão de $40 \mathrm{~T} / \mathrm{h}$, pressão de $8 \mathrm{MPa}$ e temperatura de $530^{\circ} \mathrm{C}$. A geometria da caldeira é apresentada conforme na figura (Figura 1).

No ano de 2016, uma sucessão de furos paralisou a produção de vapor na caldeira 22 de maneira emergencial por aproximadamente 548 horas totalizando uma perda de 20824 toneladas de vapor. Em função da proporção dessa falha, a caldeira em questão foi submetida a uma inspeção extraordinária de segurança conforme os dispostos na NR13. Cabe ao profissional habilitado em NR13, realizar a inspeção no equipamento pois, é sua função zelar pela integridade do equipamento, garantindo confiabilidade operacional, antecipando-se, diagnosticando e mitigando os diversos processos de deterioração [2].

$\mathrm{Na}$ inspeção da caldeira 22 foram utilizadas técnicas de caráter qualitativo, como inspeções visuais, boroscopia, análises metalográficas e outras com caráter quantitativo, como medições de espessura através de ultrassom, medições de dureza, partículas magnéticas, ensaio de líquido penetrante e análise estrutural através de elementos finitos. Pelliccione [2] afirma que são importantes o estudo teórico e a vivência prática ao se analisar uma falha, para tal foi formado um grupo multidisciplinar entre a operação, manutenção e engenharia da coqueria, profissional habilitado em NR13 e uma empresa especializada em inspeção de equipamento com objetivo de identificar o modo de falha, definir a causa raiz e implementar ações de controle para eliminar as falhas. 

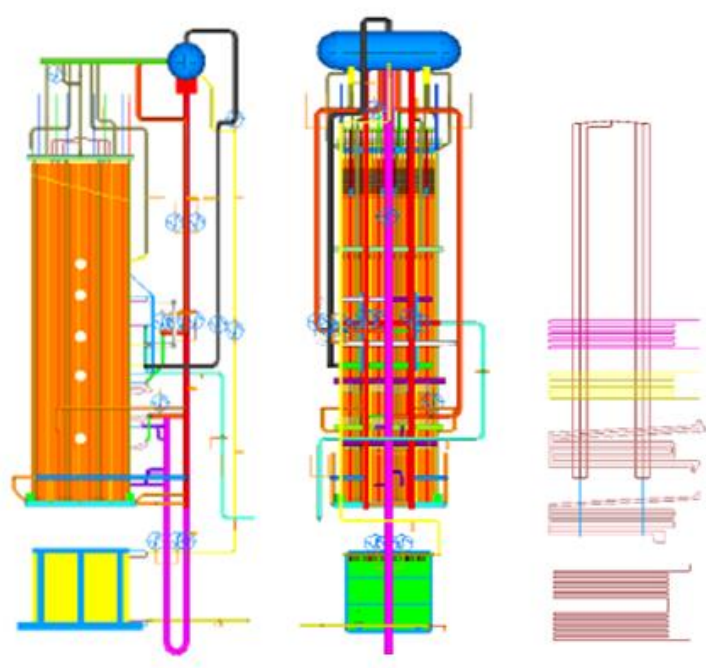

Figura 1. Caldeira de recuperação de calor de gás de coqueria vertical.

\section{RESULTADOS E DISCUSSÃO}

A falha que foi o gatilho para essa inspeção extraordinária, está localizada entre a parede de água quente e direita na parte inferior da caldeira entre o economizador e evaporador 1. A falha foi percebida pela operação através de uma queda brusca e repentina da pressão e do nível do tambor da caldeira e de um aumento repentino da pressão na linha de alimentação da caldeira. A queda de nível e o aumento da pressão da linha de alimentação causa a parada do equipamento através de um desarme, trip, de segurança. Na figura (Figura 2) podem ser observadas as dimensões dos furos e os gráficos de nível e de pressão que foram vistos na tela da operação.

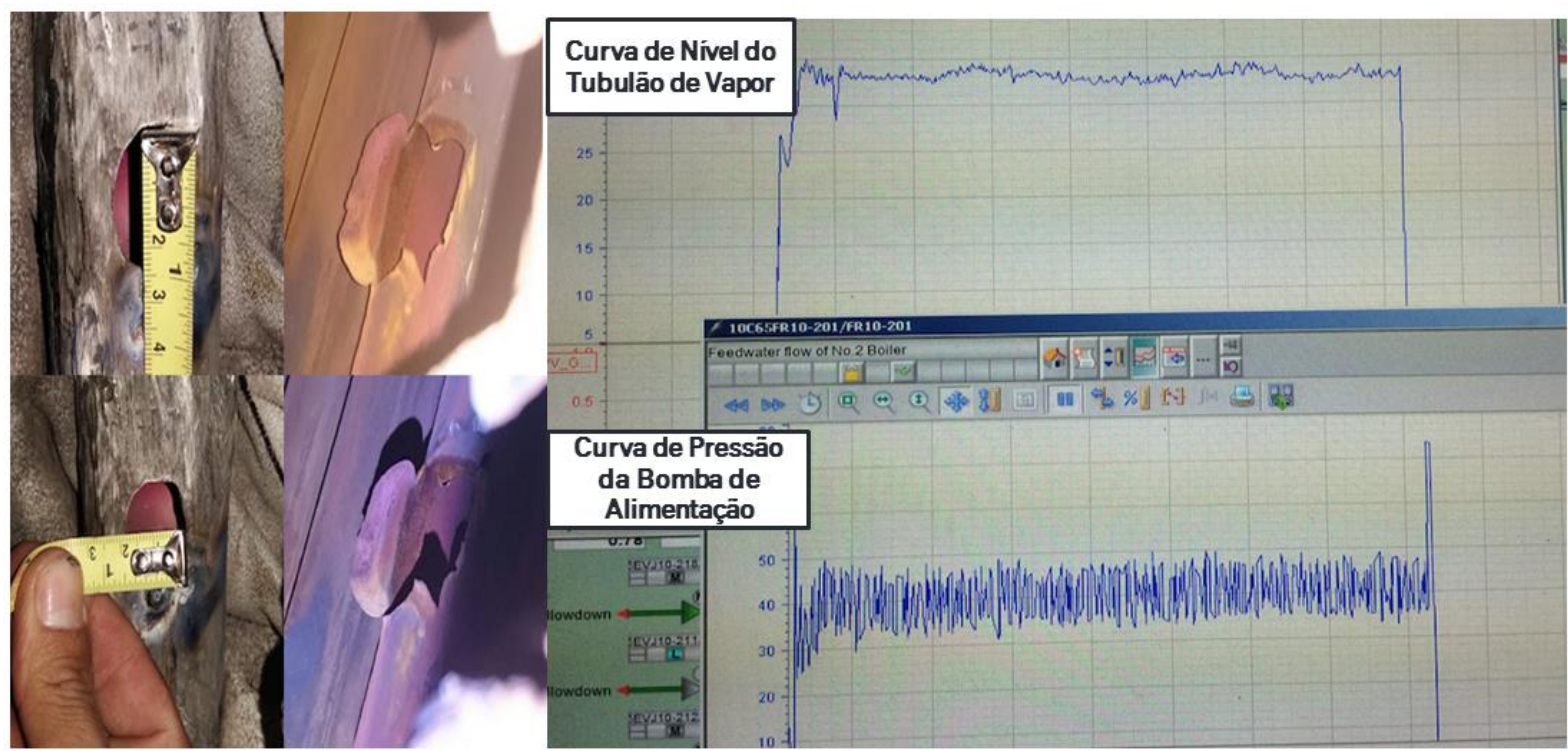

Figura 2. Furos detectados durante a inspeção e gráficos de controle na sala de operação.

A inspeção da caldeira 22 teve origem no tambor na elevação $30100(30,1 \mathrm{~m})$, conforme plano de inspeção (Figura 3), aonde foi realizada uma inspeção visual 
direta e por boroscopia e verificou-se que o lado água da caldeira se encontra em processo de corrosão em função da sua cor avermelhada que significa presença de oxido de ferro, hematita. Nas elevações a partir da cota $22200(22,2 \mathrm{~m})$ até a 5500 $(5,5 \mathrm{~m})$ foi realizado inspeção visual direta e medição de espessura e verificou-se uma boa condição geral do equipamento, com exceção da parte inferior do evaporador 1, canto da parede de água na elevação 10420 e economizador. Os resultados com as espessuras mínimas obtidos através da medição de espessura da caldeira serão apresentados na tabela (Tabela 1).

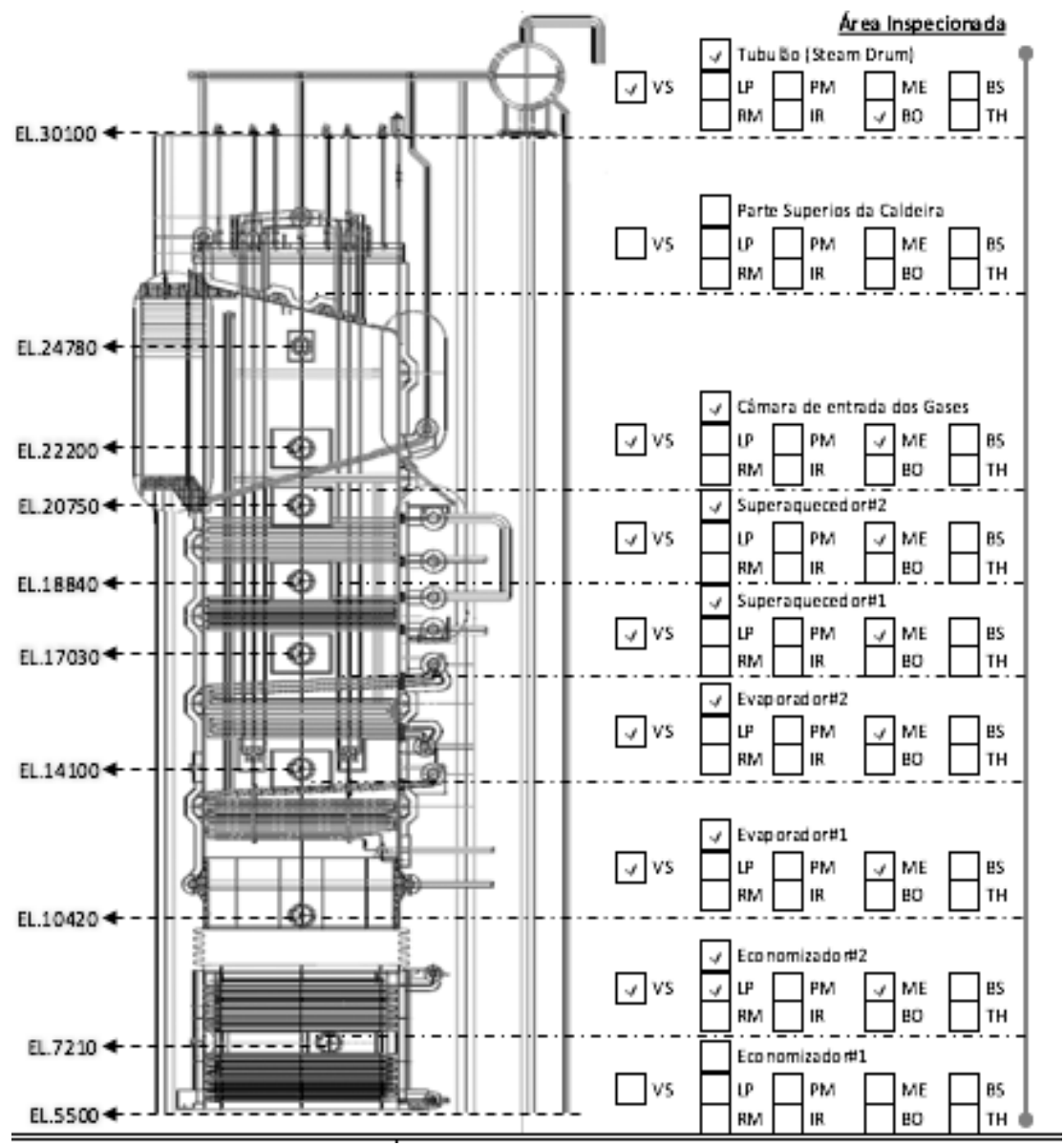

Figura 3. Plano de inspeção da caldeira

Tabela 1. Resultado da medição de espessura da Caldeira

$\begin{array}{cccccc}\text { Componente } & \text { Material } & \text { Diâmetro } & \text { E nominal } & \text { E min Cal } & \text { E min Med } \\ \text { Parede de água Fria } & 20 G & 51 & 5 & 4,2 & 4,81 \\ \text { Parede de água quente } & 20 G & 51 & 5 & 4,2 & 2 \\ \text { Parede de direita } & 20 G & 51 & 5 & 4,2 & 1,76 \\ \text { Parede de água } & 20 G & 51 & 5 & 4,2 & 4,73 \\ \quad \text { esquerda } & \text { 12Cr1MoVG } & 32 & 4 & 2,16 & 4,02 \\ \text { Super aquecedor 1 } & \text { 12Cr2MoWVTiB } & 42 & 6 & 4,44 & 6,36 \\ \text { Super Aquecedor 2 } & \text { 20G } & 42 & 5 & 3,66 & 2,04 \\ \text { Evaporador 1 } & \text { 20G } & 42 & 5 & 3,66 & 5 \\ \text { Evaporador 2 } & \text { 20G } & 38 & 5 & 2,9 & 2,16 \\ \text { Economizador } & & & & \end{array}$


A partir dos dados da inspeção foi possível determinar o reparo da caldeira nos seguintes pontos: A troca de 4 curvas do evaporador 1, (Figura 4), a troca de 11 tubos da parede de água, (Figura 5) e a troca de 21 curvas do economizador, (Figura 6).
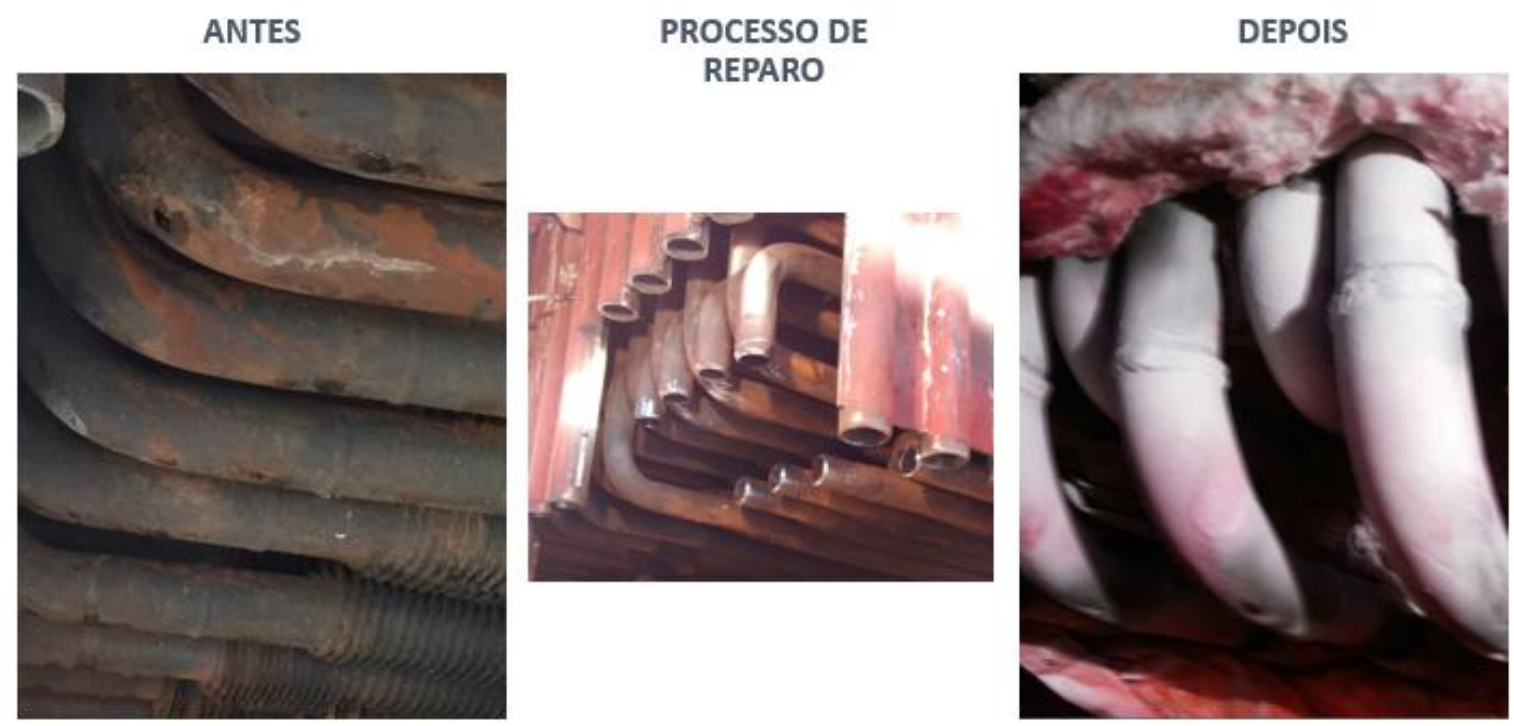

Figura 4. Evaporador 1 da caldeira

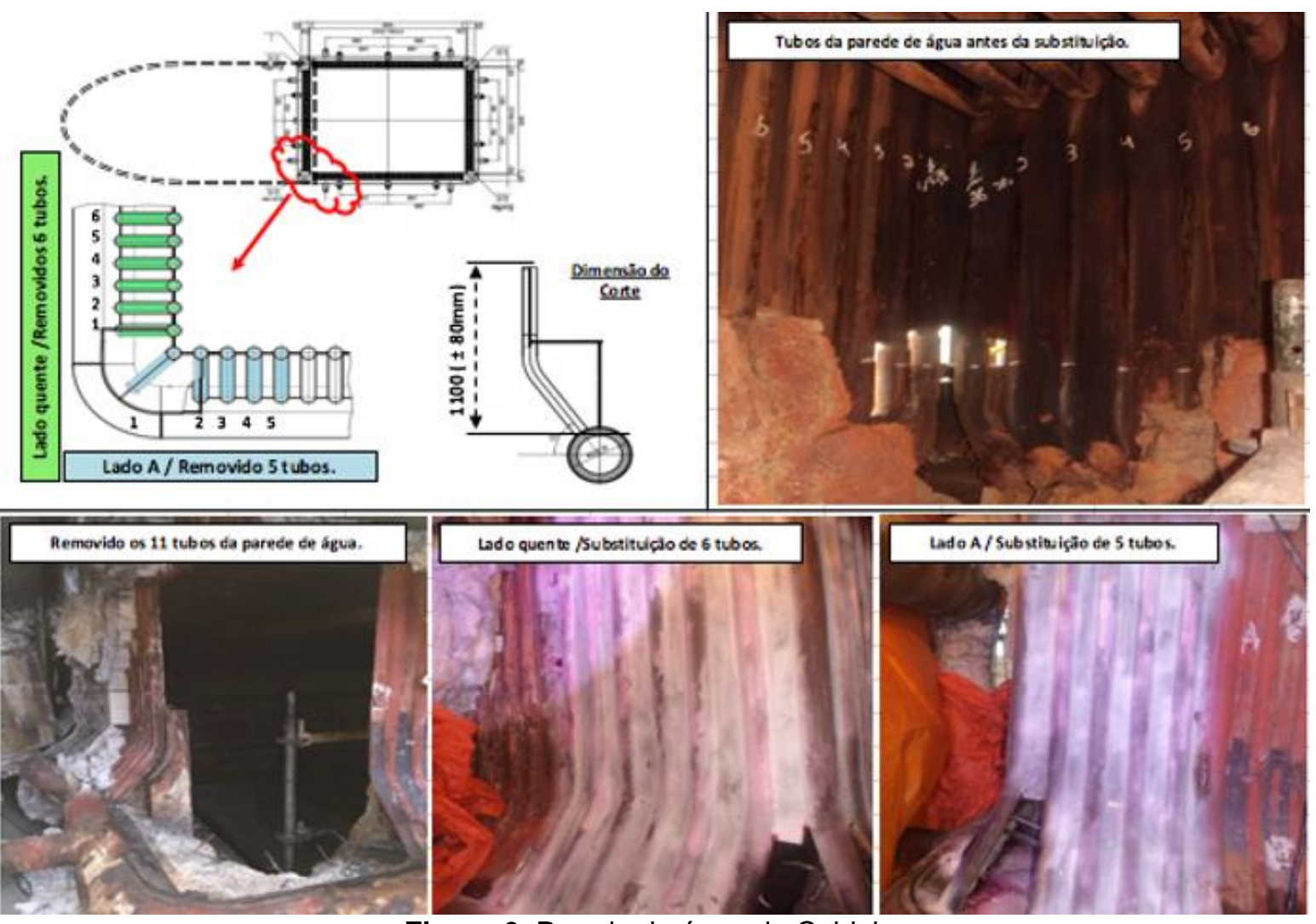

Figura 6. Parede de água da Caldeira 
ANTES

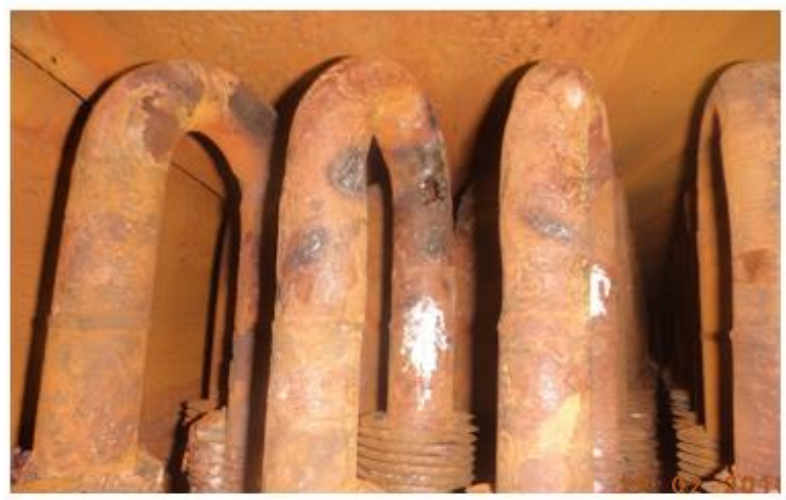

DEPOIS

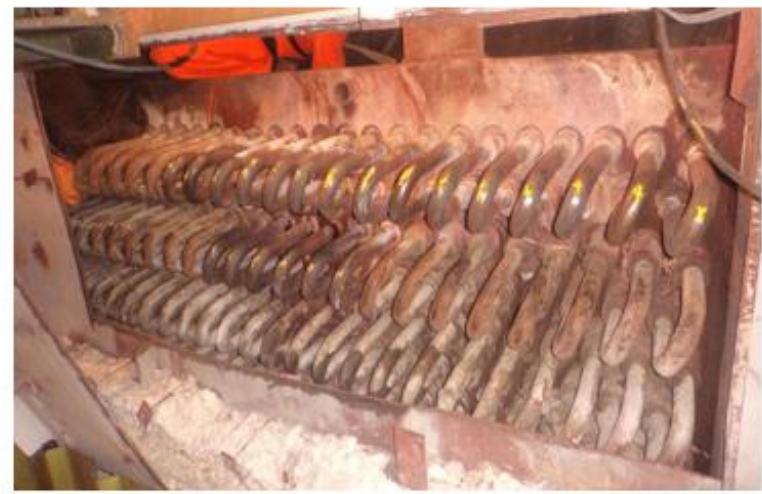

Figura 7. Economizador da Caldeira

O processo de reparo foi realizado conforme a NR13, concebido pelo profissional habilitado, determinados materiais de base de consumo, procedimentos de execução, controle de qualidade e qualificação de pessoal. A união desses fatores contribuiu de maneira significativa no resultado do reparo apresentado na tabela (Tabela 2), obtida através do resultado da inspeção do equipamento. A caldeira poderá operar por pelo menos mais um ciclo de 2 anos, ou seja até 2018, pois conforme os dispostos da NR13, caldeiras de categoria A devem ser inspecionadas de 2 em 2 anos. Deverá ser planejada uma reforma nas paredes de água, no evaporador 1 e no economizador de forma a elevar a vida remanescente da caldeira de forma uniforme.

Tabela 2. Resultado do reparo da Caldeira

$\begin{array}{cccc}\text { Componente } & \text { E min Cal } & \text { E min Med } & \begin{array}{c}\text { Vida } \\ \text { Remanescente }\end{array} \\ \text { Parede de água Fria } & 4,2 & 4,81 & 13,6 \\ \text { Parede de água quente } & 4,2 & 4,32 & 2,7 \\ \text { Parede de direita } & 4,2 & 4,45 & 5,5 \\ \text { Parede de água } & 4,2 & 4,73 & 11,8 \\ \text { esquerda } & 2,16 & 4,02 & 41,3 \\ \text { Super aquecedor 1 } & 4,44 & 6,36 & 42,7 \\ \text { Super Aquecedor 2 } & 3,66 & 3,8 & 3,1 \\ \text { Evaporador 1 } & 3,66 & 5 & 29,8 \\ \text { Evaporador 2 } & 2,9 & 4,03 & 2,9 \\ \text { Economizador } & & & \end{array}$

Como essa coqueria é equipada com 12 caldeiras, se faz necessário realizar a análise da falha do evento ocorrido para que o modo de falha seja entendido e que as ações mitigadoras sejam implementadas, o plano de inspeção seja aperfeiçoado e aplicado para todos os equipamentos semelhantes. De forma simplificada essa análise se resumirá na apresentação de um diagrama Ishikawa (Figura 8) obtido através de um brainstorming multidisciplinar, um teste de hipótese (tabela 3) que permitiu esclarecer os pontos levantados no Ishikawa e relacionar as hipóteses que 
de fato contribuíam para o mecanismo de falha e a apresentação dos 5 (Figura 9) porquês chegando a duas causas raízes.

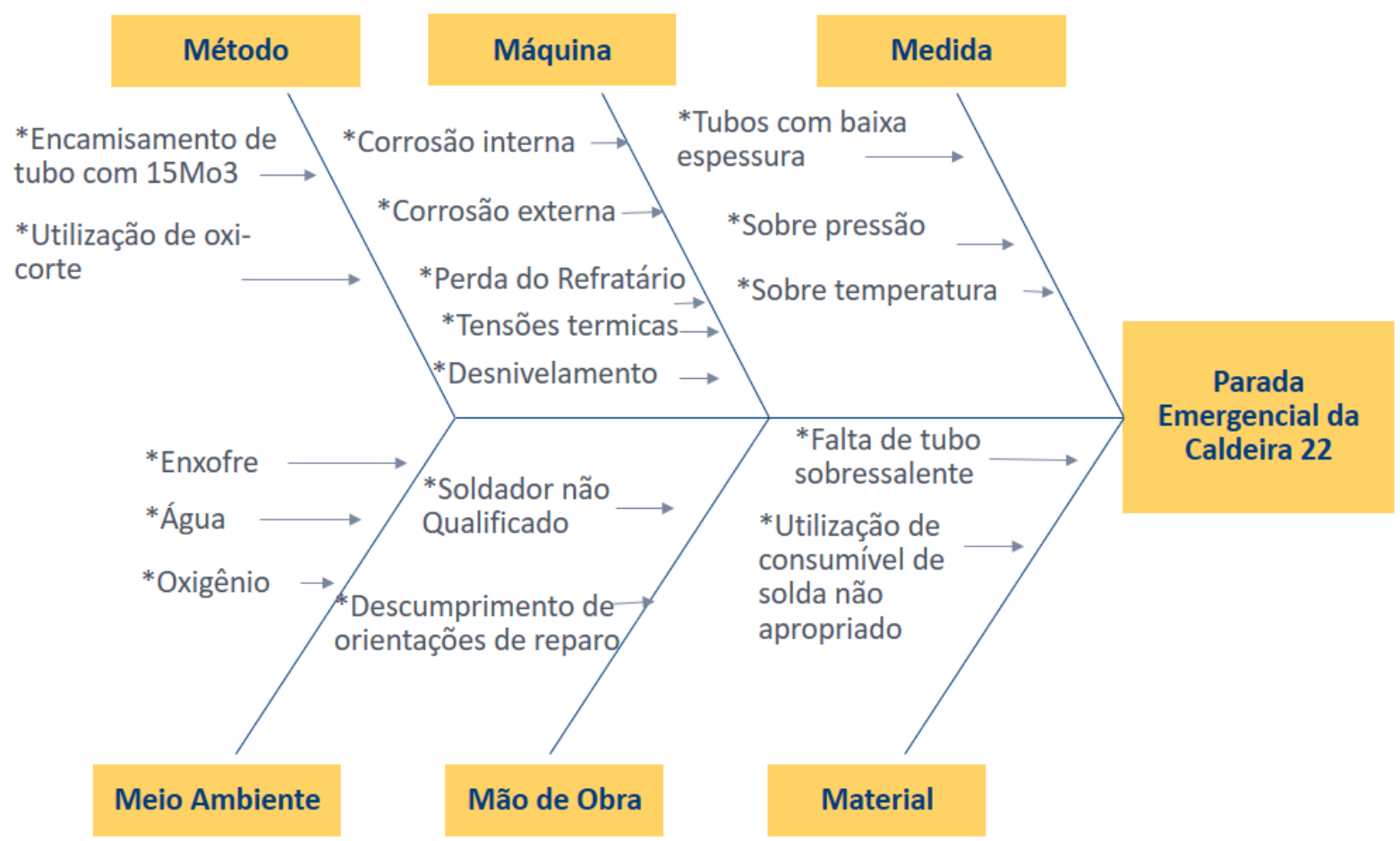

Figura 8. Diagrama Ishikawa feito na análise de falha.

Tabela 3. Teste de Hipótese

Hipótese

- Falta de Tubo

sobressalente

2 - Consumível de solda

não apropriado

3 -Soldador não qualificado

4 - Descumprimento de orientação de reparo

5 - Enxofre

HP / HD

HP

HP

HP

HP
HP

\section{Motivo}

A falta de tubo sobressalente

$$
6 \text { - Água }
$$

7 - Oxigênio faz com que a única linha de reparo seja o overlay Em reparos anteriores foi utilizado consumíveis de aço inox ou invés de aço carbono

Não há a garantia da qualidade da solda Os tubos reparados através de overlay não tinham mais condições de operação

Formação de ácido em contato com o enxofre
Por muito tempo não havia tubo sobressalent para reparo

Reparos anteriores

Reparos anteriores

Reparos anteriores Inerente ao processo

A caldeira operava ainda por alguns dias após diagnosticado o vazamento 
corrosão

8 - Encamisamento de tubos com 15Mo3

HD

9 - Utilização de Oxi corte

HD

10 - Corrosão interna

HD

11 - Corrosão Externa

12 - Perda de refratário

13 - Tensões térmicas

14 - Desnivelamento da caldeira

HD

15 - Tubos com baixa espessura

HD

16 - Sobre pressão

HD

17 - Sobre temperatura
HD HP através da junta de

$$
\text { dilatação }
$$

Fortaleceu a região do tubo aonde foi aplicado

Altera as propriedades metalúrgicas do tubo

Resultado das medições de espessura estão satisfatórios

Ao analisar o tubo foi percebido que o exterior estava descentrado A perda de refratário favorece a entrada de ar nessa parte especifica da caldeira Dilatação da caldeira em um ponto especifico

Maior influência sobre as tubulações conectadas a caldeira

O resultado da inspeção mostra uma perda de espessura pontual As curvas de operação da caleira estavam normais As curvas de operação da caleira estavam normais

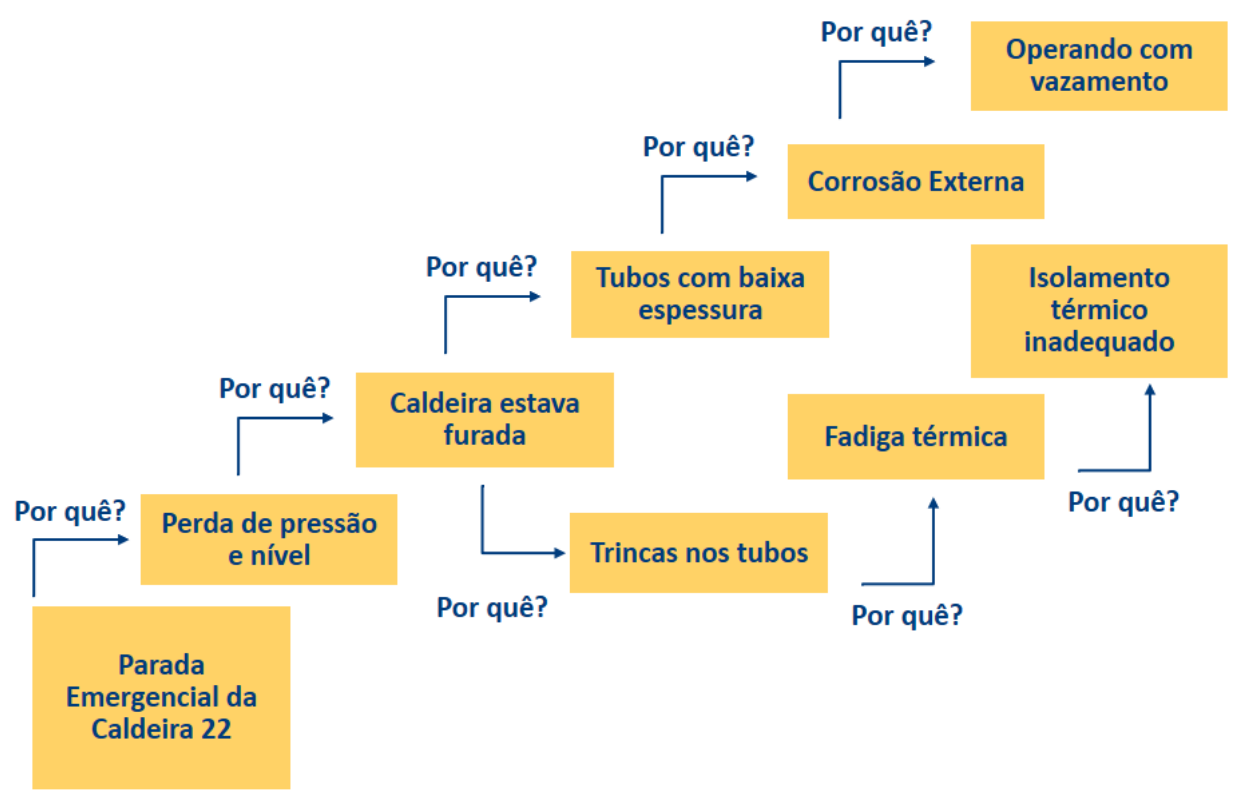

Figura 9. Diagrama dos 5 Por quês 
A partir da analise de falha realizada chegamos a duas causas raízes dessa parada emergencial. Primeiramente ao isolamento térmico inadequado para a região da caixa de selagem da caldeira que não era capaz de resistir aos gradientes de temperatura durante os ciclos de aquecimento e resfriamento do equipamento propiciando o aparecimento de trincas térmicas nessa região do canto do equipamento e seguir com a operação da caldeira com vazamento, o que resulta numa correte de fluido ácido no interior da caldeira causando uma corrosão generalizada na região atingida por esse fluxo. Na figura (Figura 10) será apresentada as duas causas determinadas como raiz da parada emergencial da caldeira 22.
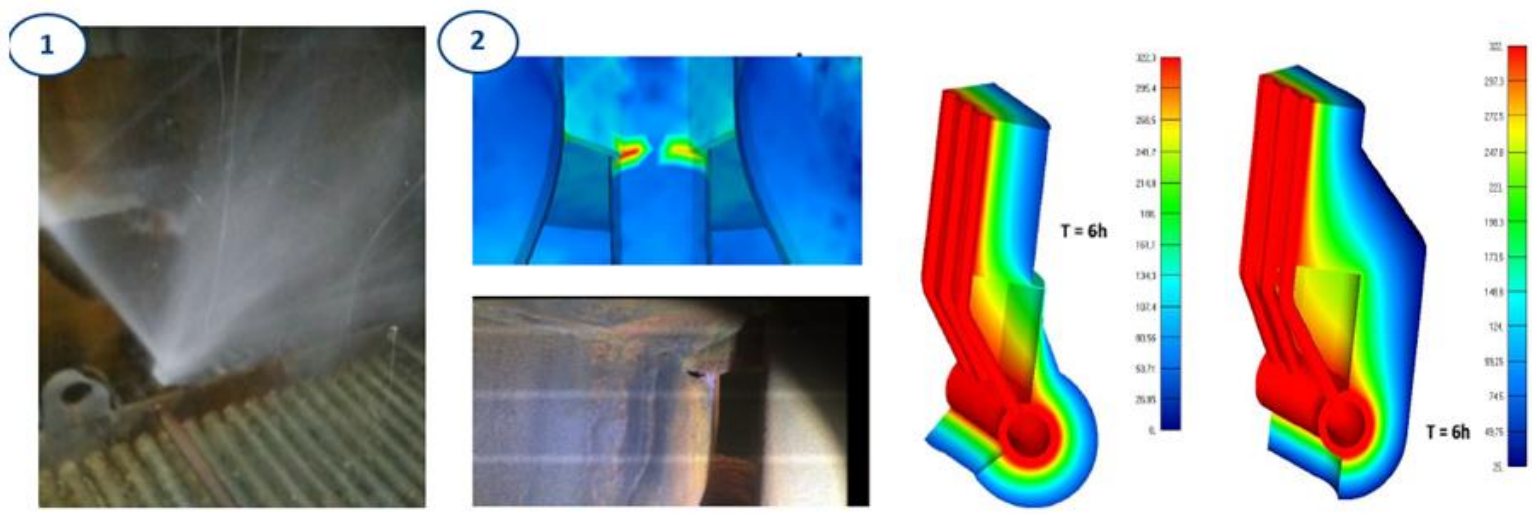

Figura 10. Imagem 1 mostrando a operação da caldeira com vazamento e a imagem 2 mostrando a correlação entre o modelo de elementos finitos e a falha real para o caso da trinca térmica em função do gradiente de temperatura gerado pelo isolamento térmico inadequado

Uma vez que foi definida as causas raízes dos modos de falha verificados durante a inspeção excepcional da caldeira 22, foram definidas as ações de controle que foram implementadas em todas as 12 caldeiras dessa coqueria em função da pane relatada. Entre as ações, podemos destacar:

- Analisar os tubos avariados em laboratório;

- Realizar análise de elementos finitos da caldeira para verificar as tensões reais;

- Realizar teste de pressão na caldeira;

- Modificar procedimento de parada de caldeira depois de detecção de um furo;

- Realizar inspeção excepcional na caldeira, para definir a falha, determinar sua abrangência e definir o reparo.

- Contratar empresa especializada para o reparo;

- Controlar a curva de resfriamento da caldeira;

- Controlar a curva de aquecimento da caldeira;

- Providenciar material sobressalente conforme especificação do equipamento;

- Modificar caixa de selagem da parede de água da caldeira;

- Aumentar espessura do isolamento térmico na região da caixa de selagem da parede de água da caldeira. 


\section{CONCLUSÃo}

O trabalho demostra o passo a passo da solução de um problema real em uma caldeira de recuperação de calor de gás de coqueria. Para a solução do problema foram utilizados os dispostos da NR13 no que diz respeito à inspeção excepcional e reparo do equipamento. Em função da repetibilidade desse equipamento nessa coqueria foi realizada uma análise de falha para se determinar as causas raízes associados aos mecanismos de dano verificados durante a inspeção.

Em função do exposto acima se chega à seguinte conclusão: Inspeções e reparos de caldeira devem ser realizados sob a responsabilidade de um profissional habilitado, reparo de caldeiras devem ser realizada por empresas especializadas com profissionais qualificados, utilizando peças sobressalentes selecionadas conforme o projeto de construção e montagem do equipamento e quando não se conhece o que levou o equipamento a falha deverá ser realizada uma análise de falha.

Para a parada emergencial da caldeira 22 as causas raízes que levaram a indisponibilidade do equipamento foram: a baixa espessura do isolamento térmico na região da caixa de selagem da parede de água, que em função dos gradientes de temperatura dos ciclos de resfriamento e aquecimento da caldeira geravam trincas térmicas, e a continuidade da operação da caldeira furada, que causava perda de espessura de uma região por corrosão devido ao fluxo de solução ácida no interior do equipamento.

O evento narrado causou uma mudança profunda na mentalidade dos profissionais que operam e fazem manutenção das caldeiras na coqueria, houve uma aproximação entre a área operacional e o profissional habilitado e possibilitou um maior conhecimento do equipamento com cascateamento das lições aprendidas para as equipes.

Desde essa falha em 2016 até a presente data, a caldeira 22 não apresentou mais nenhum vazamento, parando somente conforme a sua programação de limpeza, as ações de melhorias citadas nesse trabalho foram implantadas e em função da disponibilidade da caldeira 22 conclui-se que as ações foram satisfatórias e que o equipamento está operando em segurança conforme as especificações de projeto e em conformidade com a NR13.

\section{REFERÊNCIAS}

1 Rizzo EMS. Introdução aos processos siderúrgicos. São Paulo: ABM; 2005

2 Telles PCS. Materiais para equipamentos de processo. Sexta Edição. Rio de Janeiro: Interciência; 2013.

3 Gentil V. Corrosão. Quinta Edição. Rio de Janeiro: LTC; 2007.

4 Macintyre AJ. Equipamentos industriais e de processo, Rio de Janeiro: LTC; 2011

5 Affonso LOA. Analise de falhas e soluções de problemas. Terceira Edição. Rio de Janeiro: Qualitymark Editora; 2012

6 Pelliccione, AS. Análise de falhas em equipamentos de processo: mecanismos de danos e casos práticos. Segunda Edição. Rio de Janeiro: Interciência; 2014.

7 Kardec A, Nascif J. Manutenção: função estratégica. Terceira edição. Rio de Janeiro: Qualitymark; 2009.) 